$\frac{n}{5}$
$\frac{\pi}{0}$
$\dot{x}$
$\frac{1}{\Sigma}$
$\frac{\pi}{2}$

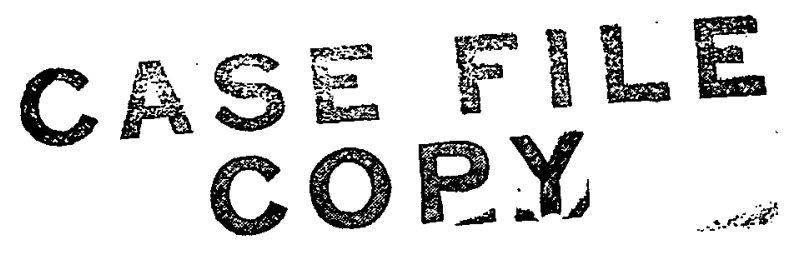

STATUS OF POWER GENERATION EXPERIMENTS IN

THE NASA LEWIS CLOSED-CYCLE MHD FACILITY

by Ronald J.Sovie and Lester D. Nichols

Lewis Research Center

Cleveland, Ohio

TECHNICAL PAPER proposed for presentation at Tenth Aerospace Sciences Meeting sponsored by the American Institute of Aeronautics and Astronautics San Diego, California, January 17-19, 1972 


\title{
STATUS OF POWER GENERATION EXPERIMENTS IN THE NASA LEWIS CLOSED-CYCLE MHD FACILITY
}

\author{
by Ronald J. Sovie, Physicist \\ and \\ Lester D. Nichols, Head, Plasma Power Generation Section \\ NASA Lewis Research Center \\ Cleveland, Ohio
}

\section{Abstract}

In this paper the design and operation of the closed-cycle MHD facility is discussed and results obtained in recent experiments are presented. The main components of the facility are a compressor, recuperative heat exchanger (preheater), heater, nozzle, MHD channel with 28 pairs of thoriated tungsten electrodes, cesium condenser, and an argon cooler. The heater can supply $1.1 \mathrm{MW}$ of thermal power to a $2.27 \mathrm{~kg} / \mathrm{sec}$ gas stream. The facility has been operated at temperatures up to $2100 \mathrm{~K}$ with a cesium-seeded argon working fluid. At low magnetic field strengths $(B=0.2 \mathrm{~T})$, the open circuit voltage, Hall voltage and short c1rcuit current obtained are 90,69 , and 47 percent of the theoretical equilibrium values, respectively. The Hall voltage and short circuit current decrease sharply with increasing magnetic field strength, however. Comparison of this data with a wall and boundary layer leakage theory indicates that the generator has shorting paths in the Hall direction.

\section{Introduction}

The primary purpose of the experimental MHD program at Lewis is to evaluate the feasibility of generating MHD power with a cesium seeded inert gas through the use of nonequilibrium ionization. The success of this method could lead to lower weight space power generation systems as well as higher-efficiency ground based power generation systems. (1) In the latter case, the increased efficlency could significantly reduce atr and thermal pollution.

The NASA-Lewis closed-cycle facility operates at input temperatures up to $2100 \mathrm{~K}$ using an argoncesium working fluid. With the exception of the cesium seed system, the loop is operated continuously at these temperatures with no cooling of the generator walls. This configuration was chosen in order to simulate better the conditions under which the generator must perform. Some system information such as durability of materials at high temperature, effects of impurities and change in performance with running time is also obtained.

The generator cross-sectional area is large compared with other facilities currently being used. (2) The large area was chosen to reduce wall friction and boundary layer effects and to provide a large volume to reduce the electron energy loss to the walls.

The theoretical performance of the Lewis (Brayton Cycle) MHD generator was evaluated by Heighway and Nichols. (3) In that analysis, the seed fraction was chosen to maximize the outputpower density for a given load voltage and operating pressure.

The purpose of this paper is to discuss the design and operation of the NASA-Lewis closed- cycle facility and to present the results obtained in recent experiments using this facility.

\section{Facility}

Genera1 Description

Figure 1 is a schematic of the closed-loop facility and figure 2 is a cutaway drawing of the high temperature components located in the test cell. The gas leaving the compressor is preheated in the parallel flow regenerative heat exchanger before entering the graphite resistance heater. On leaving the heater through the nozzle, the hot gas enters the MHD channel, expands in the diffuser and enters the shell side of the preheater. From this point conventional equipment cools, dries, and filters the gas as it flows toward the compressor. The cesium vapor is injected through a molybdenum injection tube located in the channel entrance $35 \mathrm{~cm}$ upstream of the first electrode pair. The MHD channel $(l=195 \mathrm{~cm}, w=6.35 \mathrm{~cm}$, $\mathrm{h}=19 \mathrm{~cm})$ contains 28 pairs of thoriated tungsten electrodes located in the middle of a $0.914 \mathrm{~m}$ long magnetic field region. The gas temperature at various stations in the loop and the efficiencies ( $n$ ) of the various loop components are shown in $\mathrm{flg}^{-}$ ure 1 .

\section{Heater}

The heater shown in figure 2 consists of an outer water cooled stainless stell shell, a lining of high density castable refractory cement, four graphite heater elements surrounded by magnesium oxide bricks and an inlet molybdenum flow distributor. The flow distributor evenly distributes the incoming gas through the vertical slots in the graphite heater elements. The graphite heater element at the heater exit is shown in figure 3 . The dimensions of the heater elements are 1.17 by 1.04 by $0.228 \mathrm{~m}$ and the slots provide a surface of $16.2 \mathrm{~m}^{2}$ per element for heat transfer. Hot gas, leaving the last heater element enters the heater discharge end bell and nozzle shown in figure 4. The graphite plates in the end bell are wrapped with graphite felt to protect the castable refractory which melts at $1900 \mathrm{~K}$.

The heater power supply is rated at $1725 \mathrm{kVA}$ and can raise the temperature of $2.42 \mathrm{~kg} / \mathrm{s}$ of argon from 940 to $2200 \mathrm{~K}$. Most of the runs to date have been with argon mass flows of $1.7-2.0 \mathrm{~kg} / \mathrm{s}$ and heater power levels of $1.1 \mathrm{MW}$. The heater efficiency is in the range 88-94 percent.

\section{Cesium Iniection System}

The cesium injection system schematic is shown in figure 5. When using this system, a pressure is set on the cesium pot and the control valve is opened allowing liquid cesium to flow into the vaporizer. A load cell arrangement monitors the weight of the cesium in the pot. This data is recorded on a strip chart that simultaneously records 
the Faraday open circuit voltage (at the last electrode pair). The vaporizer consists of an electrically heated Inconel spiral and molybdenum injection tube and is.shown in figure 6 . The vapor is injected along the height of the MHD channel through a series of $32,0.35 \mathrm{~mm}$ holes in the injection tube. The cesium is injected in the upstream direction to promote better cesium mixing. For the same reason a series of mixing bars is placed horizontally across the channel slightly downstream of the injection tube as shown in figure 6 .

\section{MHD Channe1}

The dimensions of the MHD channel are: length $\ell, 195 \mathrm{~cm}$; height $\mathrm{h}, 19 \mathrm{~cm}$; and width $\mathrm{w}$, $6.35 \mathrm{~cm}$. There are 28 pairs of thoriated tungsten electrodes on $2.54 \mathrm{~cm}$ centers located in the middle third of the channel. These electrodes are also located in the middle of a $0.914 \mathrm{~m}$ long magnetic field region. Figure 7 is a photograph of the channel with one side removed and shows the electrodes location and channel construction. The channel consists of a stainless steel case lined with a high density castable refractory cement. There is a layer of insulating felt between the castable refractory and the high density $\mathrm{Al}_{2} \mathrm{O}_{3}$ bricks which comprise the inner part of the channel. Sidewall electrodes are used as probes for voltage profile measurements. The molybdenum transition piece is used to mate the channel with the graphite nozzle and also houses the cesium injection tube. This arrangement keeps the cesium from getting behind the bricks with the upstream seed injection. Much care has been taken in the channel design to keep the cesium from reaching the stainless steel case at the corners and electrode feedthroughs. The electrode feed through arrangement is shown in figure 8 . With the exception of the first eight electrode pairs which are flush to the walls, the electrodes protrude $0.5 \mathrm{~cm}$ into the gas stream. Argon flows through the $\mathrm{Al}_{2} \mathrm{O}_{3}$ tubing and onto the backs of the electrode plates. This flow keeps the cesium from shorting the electrodes to the generator case and also helps cool the boundary layer on the electrode walls.

\section{Auxiliary Equipment}

The remaining equipment in the facility is fairly conventional and will be briefly described in this section.

Magnet. The water cooled magnet is rated at $330 \mathrm{~V}$ and $1500 \mathrm{~A}$ direct current. It develops a maximum uniform magnetic field of 2 tesla in the MHD channel over the generator length.

Preheater. The parallel flow regenerative heat exchanger contains 56 Inconel tubes. Each tube is 6.35 meters long and $2.54 \mathrm{~cm}$ in diameter. There is an internal lining of castable refractory protecting the outer water cooled stainless steel shell from contact with the hot gas. The temperatures of the exiting gas streams are within 20 to $30 \mathrm{~K}$ of each other as they leave the preheater, which indicates that sufficient surface area is provided for efficient energy transfer. The efficiency of the preheater varies from 65 to 80 percent depending on the gas temperature.

Cestum condenser. The cesium condenser is a single pass, counterflow, gas to mineral oil heat exchanger designed to reduce the gas temperature from a maximum value of 1200 to $340 \mathrm{~K}$, thus con. densing the cesium entrained in the flow. A sump is located at the base of the unit. Mineral oil was chosen as the coolant because it does not react with cesium. A pump circulates 1135 liters per minute ( $300 \mathrm{gal} / \mathrm{min}$ ) of mineral oil through a water cooled heat exchanger. The hot gas in the condenser flows through 129 tubes; each tube is $8.14 \mathrm{~m}$ long with a diameter of $3.18 \mathrm{~cm}$.

Argon cooler. The argon cooler is a U-shaped, counterflow, water cooled heat exchanger. To obtain an exit gas temperature of $295 \mathrm{~K}$ required at the compressor inlet, a 15 -ton $(52.9 \mathrm{~kW})$ chiller extracts the energy from the circulating cooling water. As in the condenser, the warm gas flows inside the 99 tubes. Each tube is $14.4 \mathrm{~m}$ long and has an inside diameter of $2.54 \mathrm{~cm}$.

Filters. The filters are located downstream of the argon cooler and remove solid impurities resulting from a cesium reaction with the refractory in the high temperature portion of the loop. The filter elements are of the radial fin type and are constructed of woven glass for compatibility with cesium.

Impurity purge system. As is indicated in figure 2, the heater, heater end bell, duct and preheater are lined with a castable refractory cement. This cement has been a continuing sourcé of water vapor which is decomposed by the graphite heater elements into carbon monoxide and hydrogen. These are the two major impurities found in the gas stream. The presence of these impurities can greatly reduce the nonequilibrium conductivity in the generator, especially if electrothermal instabilities are present (c.f. Bishop(4)). In order to reduce this problem, the total impurity level $\left(\mathrm{H}_{2}+\mathrm{CO}\right)$ must be kept below 0.1 percent.

Therefore, tests were run to determine the impurity generation rate as a function of gas stagnation temperature. Then, using this data a purge system was installed that changes the gas in the loop at the rate of six times an hour at $\mathrm{T}_{\text {gas }}=2100 \mathrm{~K}$. Under normal conditions this purge rate is sufficient to obtain the desired impurity levels.

Compressor. The two-stage, double acting, reciprocating compressor, operating at a suction pressure of 1.14 atmospheres absolute $\left(1.14 \times 10^{5} \mathrm{~N} / \mathrm{m}^{2}\right)$, discharges $2.42 \mathrm{~kg} / \mathrm{s}$ of argon at a pressure of 6.8 atmospheres $\left(6.8 \times 10^{5} \mathrm{~N} / \mathrm{m}^{2}\right)$ absolute and temperature of $450 \mathrm{~K}$. This compressor is designed for nonlubricated operation, having piston rings and shaft seals made from graphite impregnated tetrafluoroethylene. To prevent leakage of atmospheric air into the loop, all shaft seals are externally pressurized with argon. A $600 \mathrm{~kW} \mathrm{syn-}$ chronous motor, operating at $225 \mathrm{rpm}$ drives the compressor.

\section{Experimental Procedure}

The gas stagnation temperature and hightemperature loop components are slowly brought up to the desired temperature over a period of about 20 hours. The final adjustments of the argon mass flow and entrance Mach number are then made. The 
loop is then baked out at the operating temperature ( 2000 to $2100 \mathrm{~K}$ ) until the minimum impurity level is obtained. The cesium injection runs are then made. In these runs the desired magneticfield strength, load bank conditions, applied voltages, and any other parameters are set, and the cesium is injected for periods varying from 6 to $30 \mathrm{sec}$. During the injection time all gas properties, vaporizer temperatures, magnetic-field changes, applied power supplies, and electrode data are monitored. The Faraday voltages and currents are monitored for each electrode pair. The Hall voltage $V_{H}$ is monitored between arbitrarily selected electrodes (e.g., between electrode pairs 6 and $\left.9, V_{H 6-9}\right)$ rather than between all adjacent electrodes.

Prior to some cesium runs, external power supplies are used to run discharges from one electrode pair to another (cathode 1 to cathode 2, etc.). This discharge heats the electrodes and appears to reduce the effects of coatings which sometimes form on the electrode surfaces.

\section{Experimental Results}

Two series of experiments conducted in this facility have been previously reported. The results of the first five tests, in which the general design and structural integrity of the facility were studied, were reported in 1968. (2) These tests primarily studied the problems involved in sustaining stagnation temperatures of $2100 \mathrm{~K}$ for extended periods of time.

In the second series of tests $(5,6)$ the facility was run many times at stagnation temperatures of 2000 to $2100 \mathrm{~K}$ and an entrance Mach number of 0.38 to 0.41 . The primary objective of these tests was to obtain the proper working fluid conditions in the generator region. The generator results for these tests were characterized by reasonable open-circuit voltages ( 70 to 75 percent of theoretical) and very low short-circuit currents ( 10 percent of theoretical equilibrium values),

In this paper the results obtained in a third series of rests begun in February 1971 are presented. It was during these tests that the first power was generated under load conditions. The primary purpose of these tests was to determine what parameters were limiting the values of the current in the generator.

\section{Operating Conditions}

The operating conditions for the runs presented herein are gas stagnation pressure $\mathrm{P}_{\mathrm{H}}=2.1 \times 10^{5} \mathrm{~N} / \mathrm{m}^{2}$, gas stagnation temperature $T_{g}=2100 \mathrm{~K}$, argon mass flow rate $\dot{\mathrm{M}}_{\mathrm{A}}^{\mathrm{g}}=1.5-1.7 \mathrm{Kg} / \mathrm{s}$, entrance Mach number $M=0.31-0.34$, gas velocity $\mu=270-290 \mathrm{~m} / \mathrm{s}$, cesium seed fraction $S=0.03-0.4$ percent, impurity level $\mathrm{H}_{2}+\mathrm{CO}=0.15$ percent, and magnetic field strength $B=0-1.5 \mathrm{~T}$.

\section{Variation Along the Channel Length}

The variation of the open circuit voltage, $v_{o c}$, along the channel length is shown in $\mathrm{fig}^{-}$ ure 9. The theoretical value $u B h$ is also indicated on the figure. The figure shows that the open circuit voltage is quite uniform along the channel and that there are no severe end effects. No data is plotted for electrodes 1,3 , and 5 because these electrodes were lost in an earlier cesium test.

\section{Variation with Magnetic Field Strength}

The variation of the open circuit voltage, $\mathrm{v}_{\mathrm{oc}}$, the short circuit current per electrode pair, $I_{S C}$, and Hall voltage $V_{H}$ with magnetic field strength is shown in figure 10. The open circuit voltage is seen to increase fairly uniformly with $B$ whereas the short circuit current goes through a maximum at $B=0.28 \mathrm{~T}$. For the operating conditions for this data, the theoretical value of the Ha1l parameter $\beta$ would be 1.2 at $B=0.28 \mathrm{~T}$. The Hall voltage is seen to flatten out with increasing $B$. This trend coupled with the decreasing short circuit current values at higher $B$ indicate that the generator has an internal leakage resistance in the Hall direction.

The ratios of the measured $V_{O C}, V_{H}$, and $I_{S C}$ to the ideal equilibrium values $u B h, k_{l} \beta u B l$, and $\mathrm{k}_{2} \sigma \mathrm{uBA} \mathrm{y}$ are plotted versus magnetic field strength in figure 11. $\sigma$ is the electrical conductivity, $\beta$ is the Hall parameter, and $k_{1}$ and $k_{2}$ are correction factors which account for segmentation effects (Dzung(7)). The values of $\sigma$ and $\beta$ have been calculated by assuming that the liquid cesium flow into the vaporizer is fully vaporized. The figure shows that open circuit voltages as high as 90 percent of the theoretical value are obtained at relatively high magnetic field strengths. The Hall voltage and short circuit current are 69 and 47 percent of the ideal values at low $B$. The very sharp decrease in these ratios with increasing $B$ is an indication of severe internal shorting in the Hall direction.

\section{Hall Shorted Tests}

As a test of the severity of the internal Hall shorting, the top electrodes were shorted together externally and so were the bottom electrodes. That is, the generator was run with essentially continuous electrodes and the data were taken through a single variable load resistor. The current obtained was lower than that for the segmented tests indicating that at least the internal Hall leakage resistance was not zero. The current-voltage curve for the Hall shorted test is shown in figure 12. The ideal curve is also shown for comparison. For this case, the theoretical plasma resistance is given by $R_{t h}=h\left(1+\beta^{2}\right) / \sigma_{t h} A_{\text {. }}$. For the condition shown in figure 12 , the calculated resistance is $1.8 \mathrm{ohms}$ and the measured resistance is $2.3 \mathrm{ohms}$. We believe that the discrepancy is due to the fact that the cesium being injected into the plasma is not fully vaporized thus lowering the effective seed rate. For our operating conditions the conductivity is not a strong function of seed rate but the Hall parameter decreases sharply with increasing seed rate.

\section{Voltage Profile Results}

The voltage profile across the channel at electrode pair 25 for open and closed circuit condition is shown in figure 13. The figure shows that the open circuit voltage is generated quite uniformly across the channel. In the short circuit case it appears that the plasma does not fully see 
the external short circuit. There is also a large voltage drop at the anode. This anode drop is better illustrated in figure 14, where we have plotted the voltage drop across the channel; $u B \hat{y}-V_{\text {meas }}$, versus the channel height with $B$ as a parameter. The anode potential is used as a reference in this figure. The figure shows that the voltage gradient across the center of plasma is fairly constant. The cathode drops are small indicating that there is good cesium coverage of this electrode. There are large anode drops, however, and these increase with magnetic field strength. These anode drops may be measured because of the position of the profile probes.

In a segmented generator, the current flows out of the trailing edge of the cathode and into the leading edge of the anode. The electric field in the generator is therefore not constant near and parallel to the surface of the electrode. If the profile electrodes are slightly upstream of the plane joining the middle of the anode to the middle of the cathode, then the voltage may change more rapidly near leading edge of the anode than the cathode. On the other hand, if the electrodes were slightly downstream of the plane joining the center of the electrodes, then large cathode drops would be measured.

The behavior of the generator can be put in agreement with the leakage theory (e.g.,

Hoffman (8), when combined with the finite segmentation results (Dzung ${ }^{(7)}$ ). This agreement can be achieved by adjusting two parameters; the actual seed fraction and the Hall shorting resistance. It turns out that if one assumes that about 25 percent of the seed that is injected is vaporized in the duct, and that the shorting path is a loop from the back of the generator to the reheater (which is grounded) and from the vaporizer tube (which becomes grounded when cesium is present) to the front of the generator, then good agreement between the calculated values and the measured values can be obtained.

A further check was made experimentally. Since the leakage theory states that the Faraday current is prevented from flowing because the Hall voltage is shorted, a Hall voltage was applied and the Faraday current measured. The current increased just as the leakage theory would predict. The amount of power required to provide this Hall voltage increases with decreasing Hall leakage resistance, so it is not always a useful way of increasing the power output of the generator.

\section{Concluding Remarks}

The NASA Lewis closed-cycle MHD facility has been run 21 times at temperatures up to $2100 \mathrm{~K}$. Operation of the facility is quite routine now and very few problems arise when running at high temperatures for extended periods of time.

Analysis of the data has shown that there are two problems that are limiting the generator performance. The liquid seed is not fully vaporized when injected into the gas stream and there is internal Hall shorting in the generator. In order to remedy these problems, a new cesium atomizer is presently being tested and the heater end bell and preheater are being floated from ground.

\section{References}

1. SeikeI, G. R. and Nichols, L. D., "The Potential of Nuclear MHD Electric Power Systems," Paper 71-638, June 1971, AIAA, New York, N.Y.

2. Nichols, L. D., Morgan, J. L., Nagy, L. A. Lamberti, J. M., and Ellson, R. A., "Desígn and Preliminary Operation of the Lewis Magnetohydrodynamic Generator Facility," TN D-4867, 1968, NASA, Cleveland, Ohio.

1

3. Heighway, J. E. and Nichols, L. D., "Brayton Cycle Magnetohydrodynamic Power Generator with Nonequilibrium Conductivity," TN D-2651, 1965, NASA, Cleveland, Ohio.

4. Bishop, A. R. and Nichols, L. D., "Conductivity of an Impure, Nonequilibrium Plasma with Electrothermal Instabilities," AIAA Journal, Vol. 8, No. 4, Apr. 1970, pp. 829-831.

5. Sovie, R. J. and Nichols, L. D., "Results of Initial Subsonic Tests in the NASA-Lewis Closed Loop MHD Generator," Proceedings of the 11th Symposium on Engineering Aspects of Magnetohydrodynamics, D. G. Elliott, ed., University of Mississippi, 1970, pp. 82-89.

6. Sovie, R. J. and Nichols, L. D., "Results Obtained in NASA Lewis Closed-Cycle Magnetohydrodynamic Power Generation Experiments," TM X-2277, 1971, NASA, Cleveland, Ohio.

7. Dzung, L. S., "Favourable Configurations of Segmented Electrodes for MHD Generators," Brown Boveri Review, Vol. 53, No. 3, Mar. 1966, pp. 238-250.

8. Hoffman, M. A., "Simplifled Analytical Models for Wall and Insulator Boundary Layer Losses in Non-Equilibrium MHD Generator," $\mathrm{CD} / 21 / 1$, July 1967, Comitato Nazionale per L'Energia. Nucleare, Frascoti, Italy. 


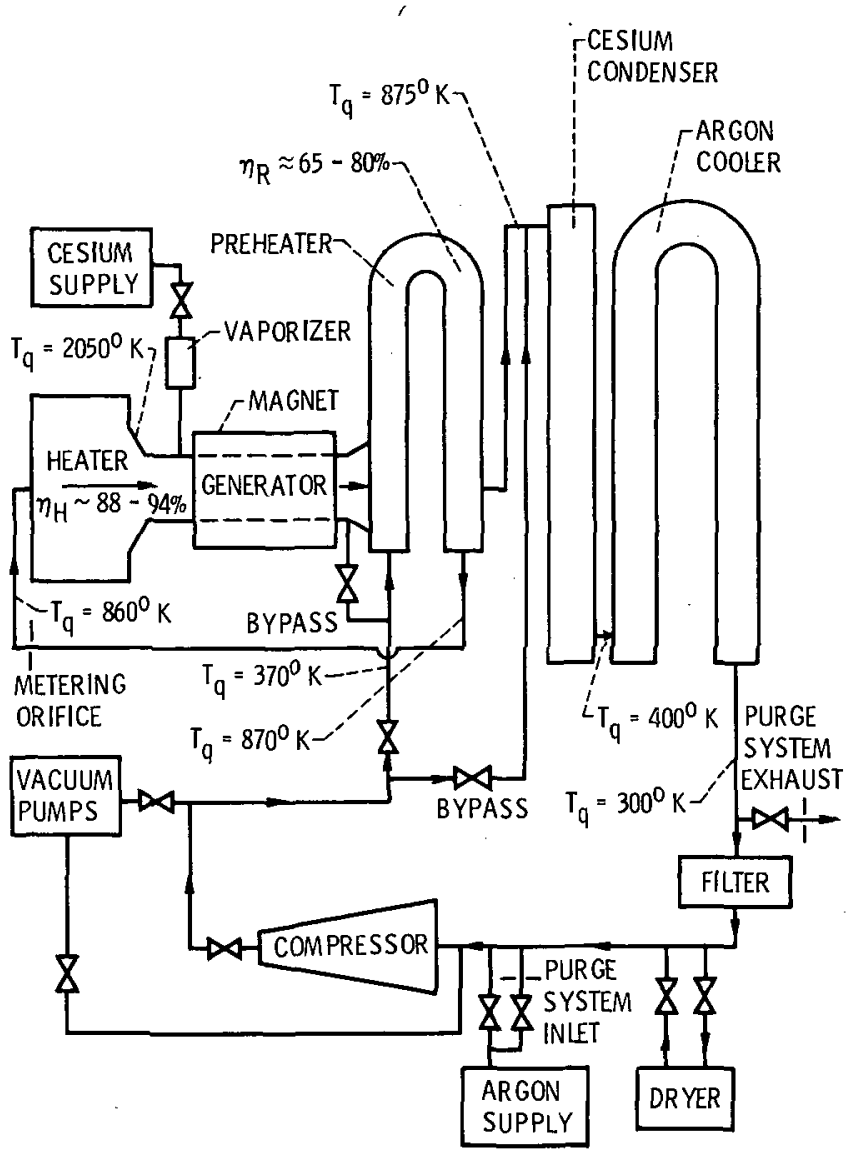

Figure I. - Loop schematic.

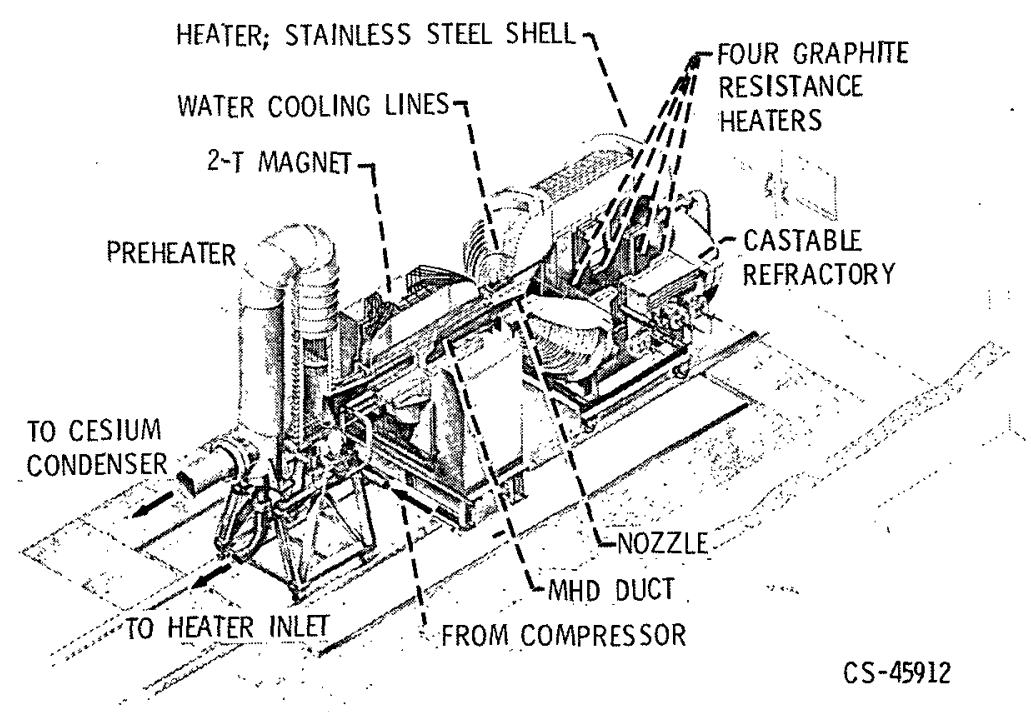

Figure 2. - Bedplate showing heater, nozzle MHD duct, magnet, and reheater. The flow distributor at the heater in let is not shown. 
$m$
$\sigma$
0
$\vdots$
1
1
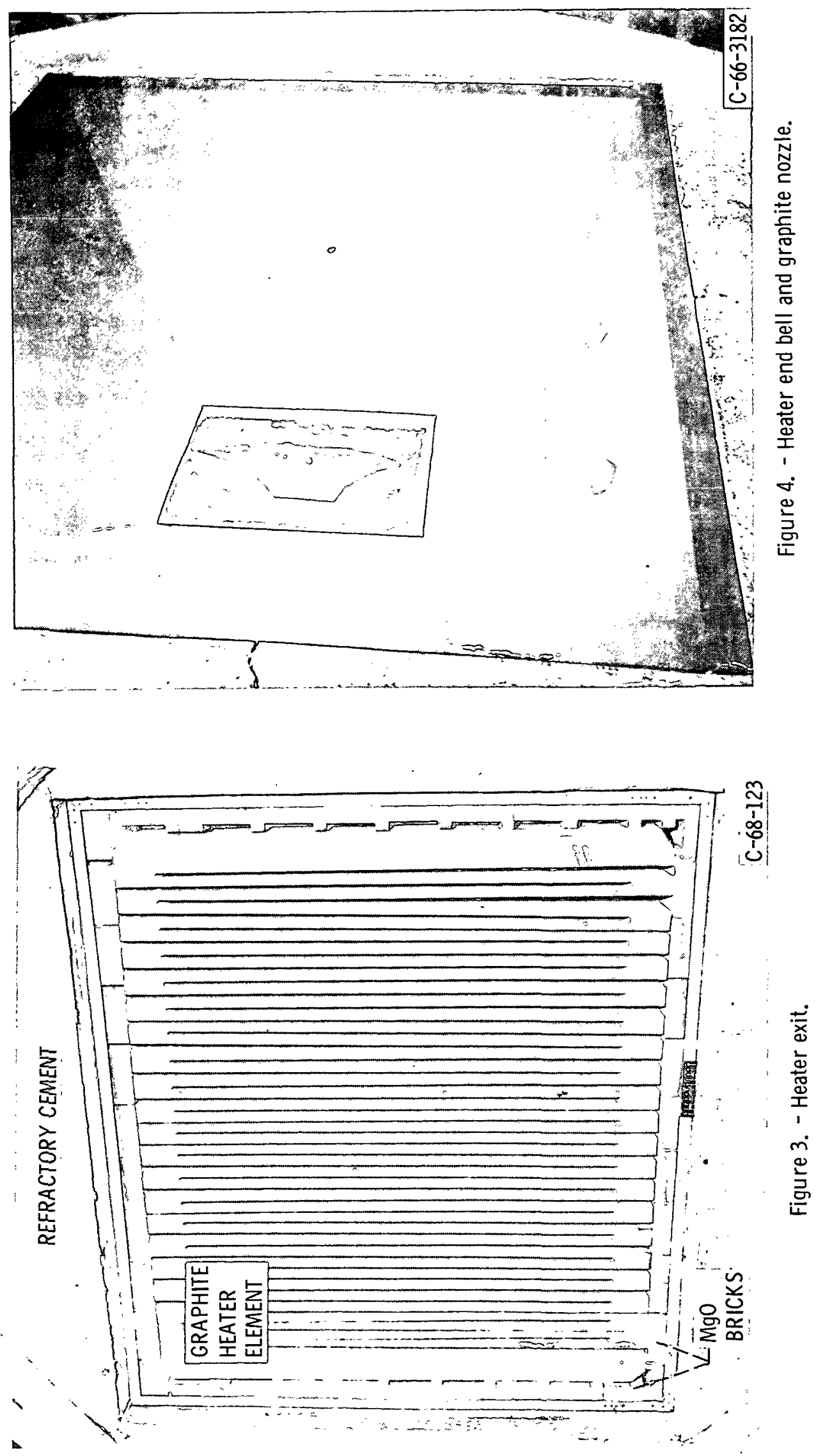


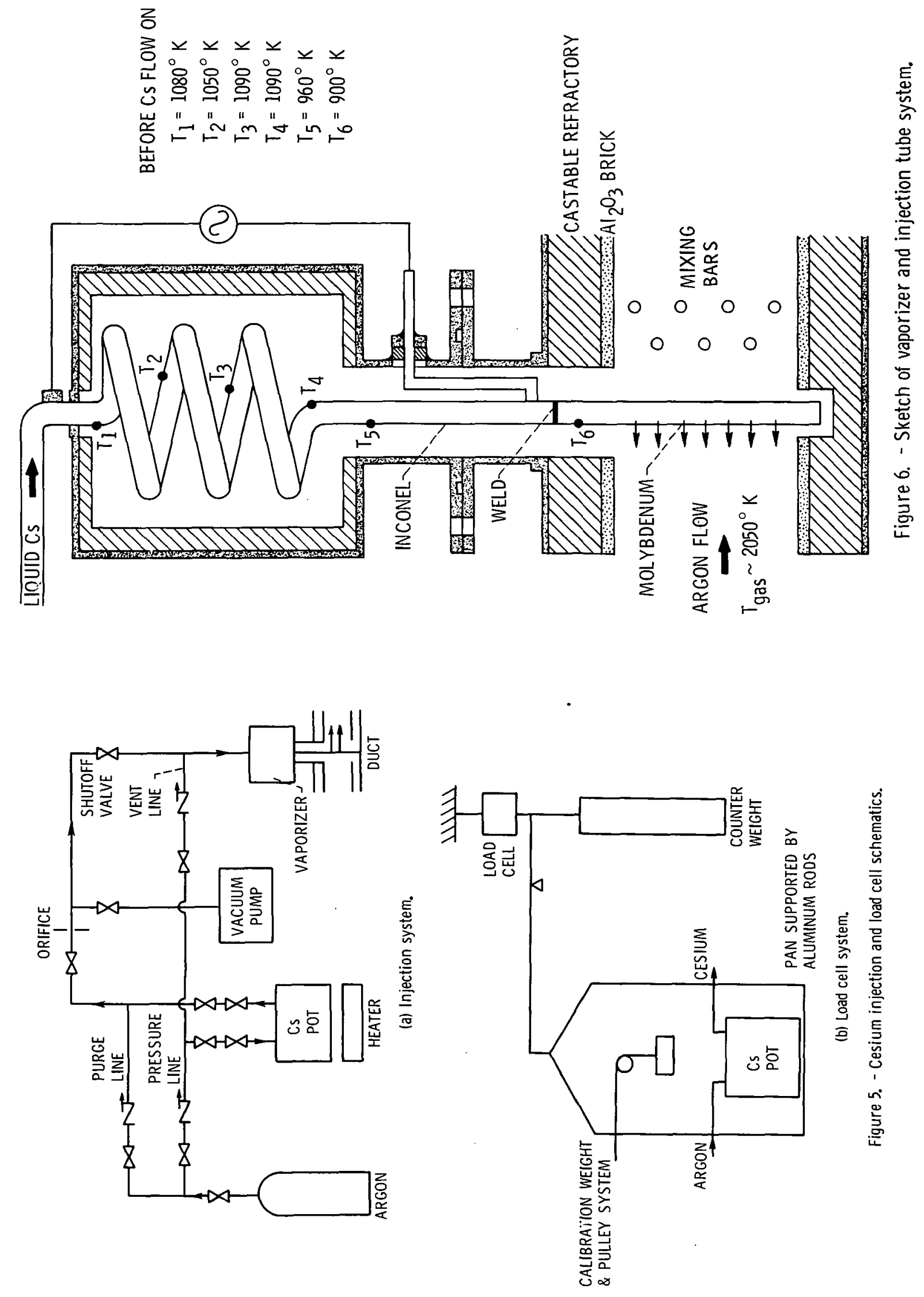

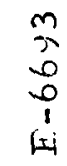




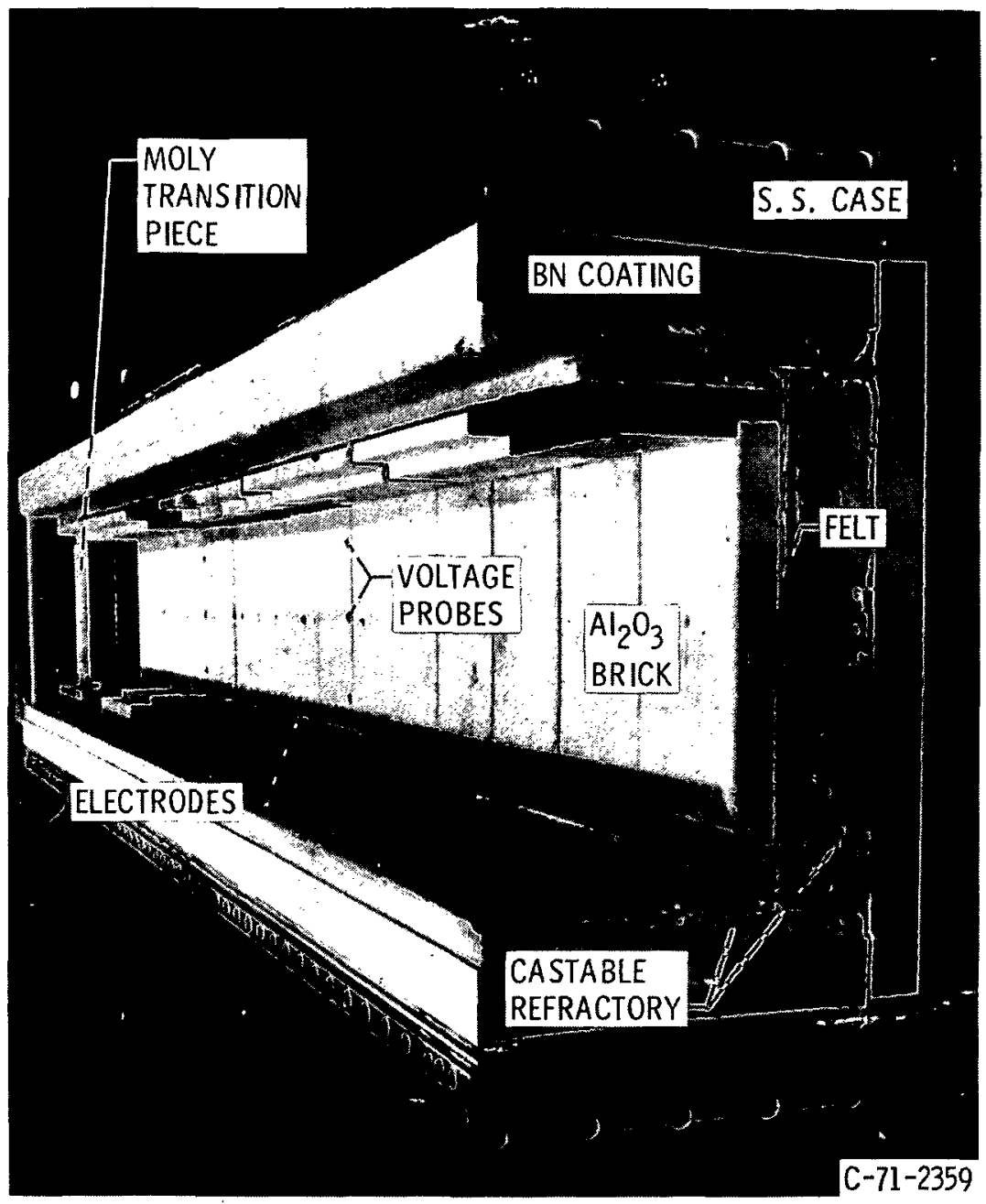

Figure 7. - MDH channel.

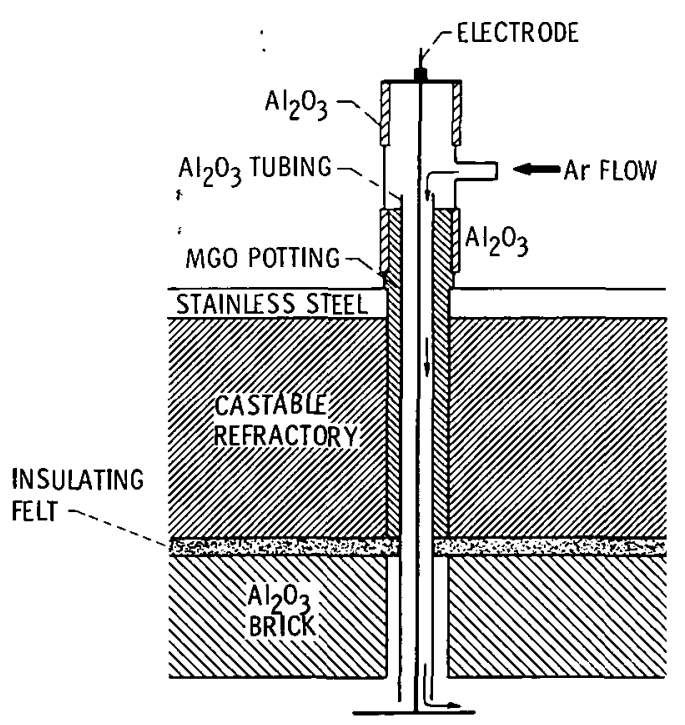

Figure 8. - Electrode feed through arrangement. 


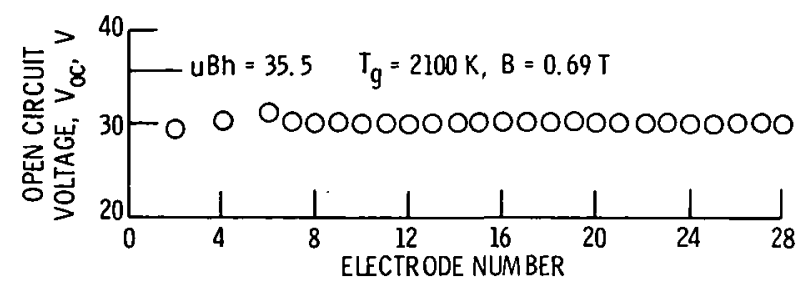

Figure 9. - Variation of open circuit voltage along channel.

$m$
0
0
0
1
is

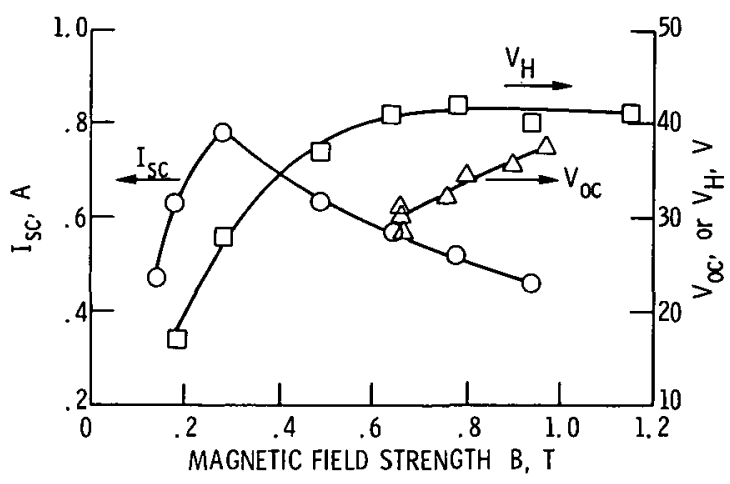

Figure 10. - Variation of open circuit voltage, $V_{o c}$, Hall voltage, $V_{H}$, and short circuit current per electrode pair, $I_{S C}$, with magnetic field strength.

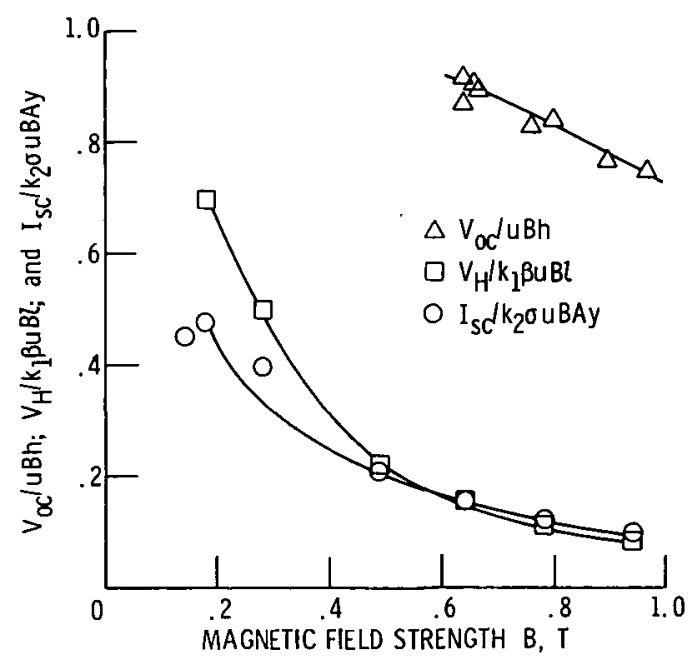

Figure 1l. - Variation of $V_{o} J u B h, V_{H} / k_{1} \beta u B l$, and $\mathrm{I}_{S C} / \mathrm{k}_{2} \mathrm{OUBA}$ y with magnefic field strength. 


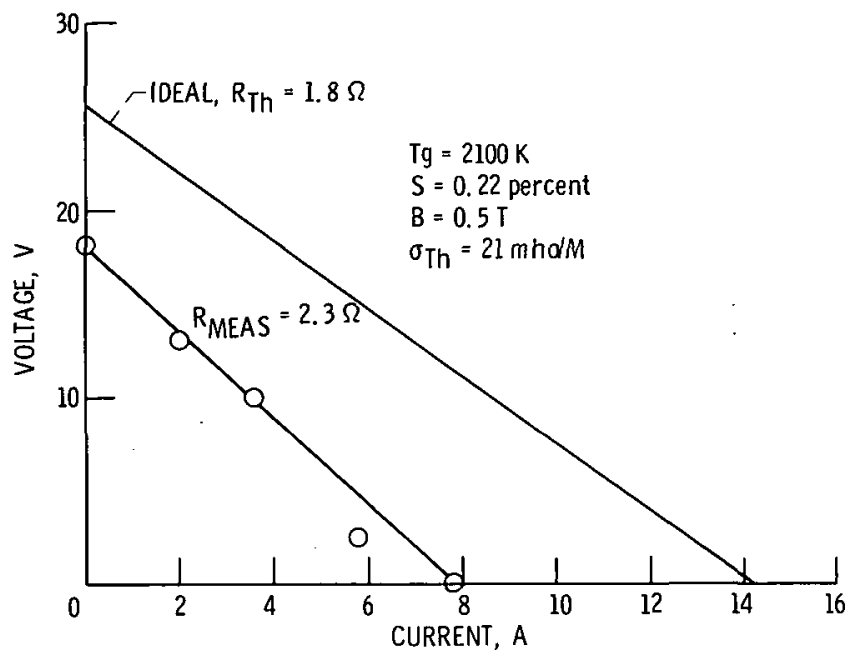

Figure 12. - Current-voltage data for Hall shorted test.

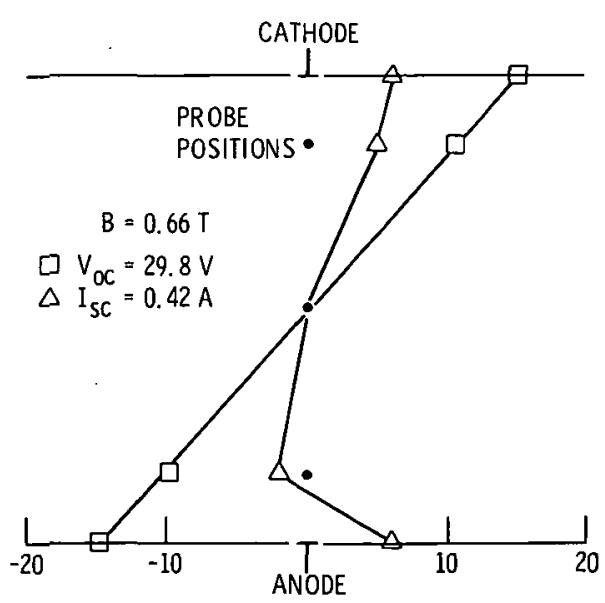

VOLTAGE WITH RESPECT TO CHANNEL CENTERLINE, V

Figure 13. - Voltage profile between anode and cathode of electrode pair 25 at open and short circuit conditions.

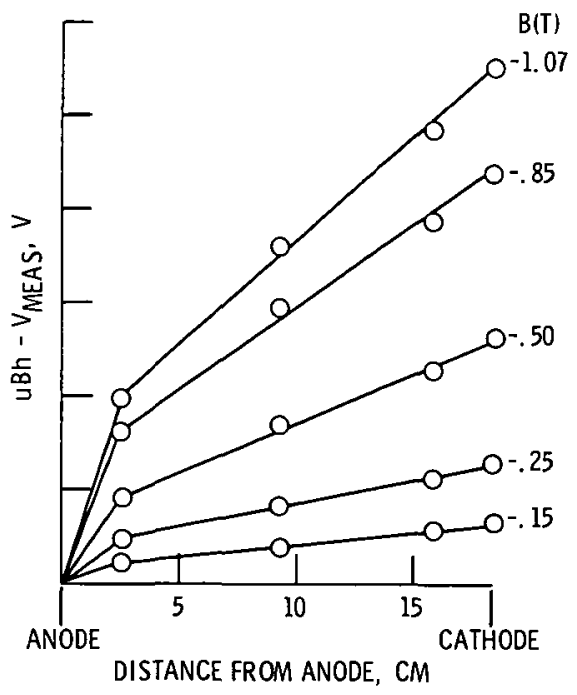

Figure 14. - Variation of voltage drop in plasma uBh $-V_{M E A S}$ with distance from anode and magnetic ffeld strength. 